\title{
MELHORIA DA LAMINABILIDADE A FRIO DO AÇO SAE 1070 PRODUZIDO NA APERAM SOUTH AMERICA*
}

\author{
Francisco Geraldo Toledo Junior ${ }^{1}$ \\ Henrique de Castro Rodrigues ${ }^{2}$ \\ Keyferson Gonçalves Ferreira ${ }^{3}$ \\ Marcio Aurélio Gomes Fernandes ${ }^{4}$ \\ Valdeci Paula Alvarenga ${ }^{5}$
}

\section{Resumo}

Os aços alto carbono possuem maior resistência e dureza, e menor dutilidade em relação aos aços baixo e médio carbono. O aço carbono SAE 1070 é um aço plano classificado como alto carbono e possui uma microestrutura predominantemente perlítica. Algumas possíveis aplicações desse aço são: fitas de serra, lâminas para raspagem, lâminas de corte para indústrias agrícolas, entre outros. 0 processamento desses de aços em toda a cadeia produtiva sempre é desafiadora. $O$ objetivo principal foi caracterizar e melhorar a microestrutura perlítica do aço SAE 1070 laminado a quente produzido na Aperam visando reduzir ou eliminar o custo adicional dos clientes de relaminação durante o processamento em suas linhas de produção. Foi possível através de análises e simulação termodinâmica refinar o grão austenítico e melhorar as propriedades mecânicas do aço SAE 1070 produzido na Aperam e como consequência a melhoria da laminabilidade a frio desse aço.

Palavras-chave: Laminação a Frio; SAE 1070; Espaçamento Interlamelar; Refino de Grão.

\section{IMPROVEMENT OF COLD LAMINABILITY SAE 1070 PRODUCED IN APERAM SOUTH AMERICA}

\section{Abstract}

High carbon steels have higher strength and hardness, and lower ductility than low and medium carbon steels. SAE 1070 carbon steel is a high carbon flat steel with a predominantly pearlite microstructure. Some possible applications of this steel are: saw bands, scraping blades, cutting blades for agricultural industries, among others. The processing of these steels throughout the production chain is always challenging. The main objective was to characterize and improve the pearl microstructure of SAE 1070 hot-rolled steel produced at Aperam to reduce or eliminate the additional cost of re-rolling customers during processing on their production lines. It was possible through thermodynamic analysis and simulation to refine the austenitic grain and to improve the mechanical properties of SAE 1070 steel produced in Aperam and as a consequence the improvement of the cold laminability of this steell

Keywords: Cold Rolling; SAE 1070; Interlamellar Spacing; Grain Refining.

1 Engenheiro, Mestrando em Engenharia de Materiais, Engenheiro de Processo na APERAM, Timóteo, Minas Gerais, Brasil.

2 Engenheiro, Mestre em Engenharia Metalúrgica, Gerente na APERAM, Timóteo, Minas Gerais, Brasil.

3 Engenheiro, Analista Técnico na APERAM, Timóteo, Minas Gerais, Brasil.

4 Engenheiro, Analista Técnico na APERAM, Timóteo, Minas Gerais, Brasil.

5 Engenheiro, Mestre em Engenharia de Materiais, Engenheiro de Processo na APERAM, Timóteo, Minas Gerais, Brasil, 


\section{INTRODUÇÃO}

O aço carbono SAE 1070 é um aço plano classificado como alto carbono e possui uma microestrutura predominantemente perlítica. Permite uma vasta possibilidade de aplicações onde o requisito principal é a elevada resistência mecânica. Algumas possíveis aplicações desse aço são: fitas de serra, lâminas para raspagem, lâminas de corte para indústrias agrícolas, entre outros.

O espaçamento interlamelar da microestrutura perlítica possui forte influência nas propriedades mecânicas dos materiais durante os processos de deformação a frio. Materiais com espaçamento interlamelar menor (perlita fina) possuem melhores propriedades mecânicas e como conseqüência tem alcançado altas taxas de deformação a frio. Por outro lado materiais com espaçamento interlamelar maior (perlita grossa) tem alcançado taxas menores de deformação a frio (SERENO, et al, 2013).

Segundo Camargo(2), com a condição de espaçamento interlamelar visualmente menor (perlita fina), a deformação a frio atingiram níveis de $91 \%$ em aços alto carbono SAE 1080, o que demonstrou a capacidade das lamelas estreitamente espaçadas se encruarem exponencialmente, atingindo assim, propriedades mecânicas elevadas, mesmo contendo cementita, conhecidamente uma fase frágil.

Quando se trabalha com aços com microestrutura perlítica grosseira, empresas de relaminação têm utilizado do recurso de recozimento intermediário para alcançar altas taxas de deformação e como conseqüência aumento do custo de processamento destes materiais. A figura 1 ilustra o fluxo de processos típicos utilizados por essas empresas em materiais com microestrutura perlítica fina e grosseira.

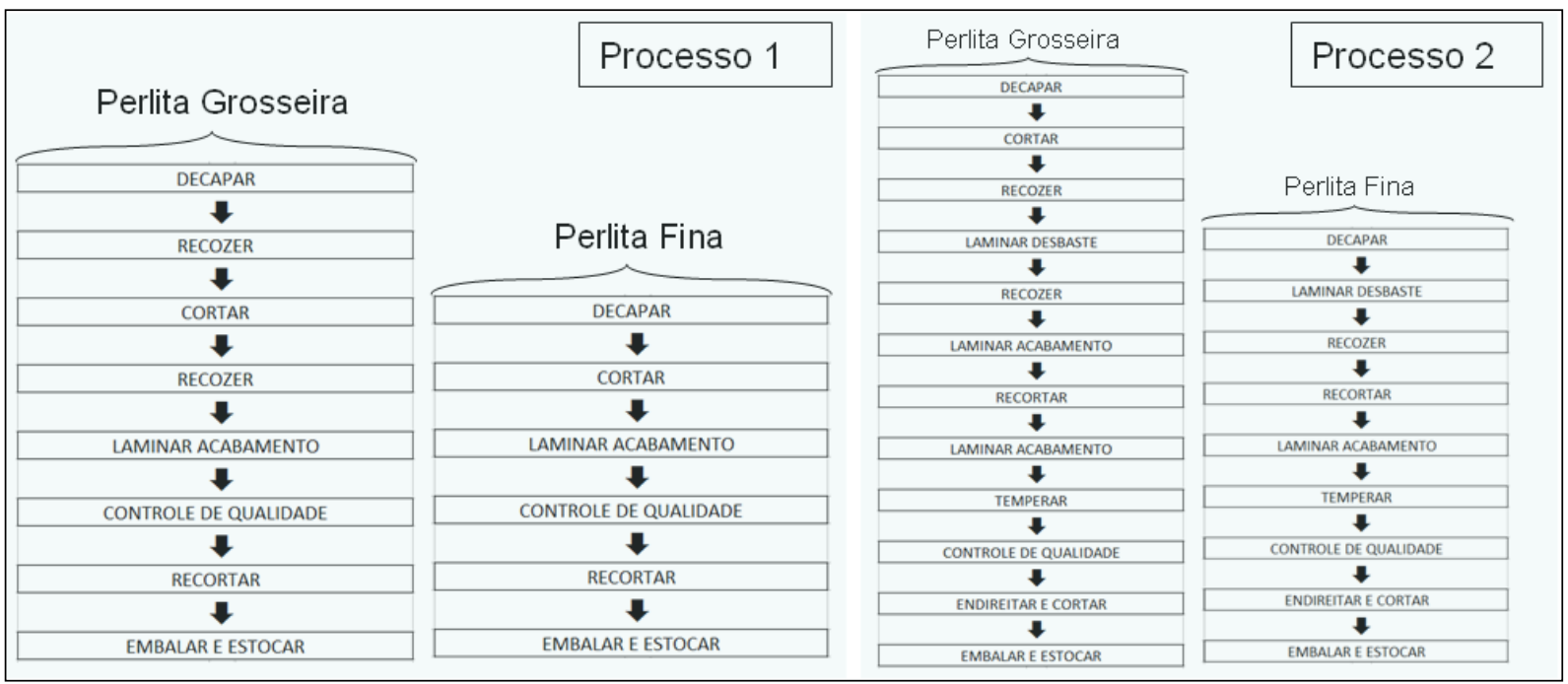

Figura 1. Fluxo de processos utilizado pelo cliente Brasmetal em função da microestrutura

O menor tamanho de grão austenítico provoca maior nucleação de nódulos perlíticos e como conseqüência uma microestrutura perlítica mais fina e melhores propriedades mecânicas dos aços. Segundo a literatura o tamanho de grão austenítico não tem influencia na espessura da lamela. Para certa temperatura, a taxa de nucleação e difusão determinará o espaçamento (COLPAERT, 2008). 
O crescimento do grão austenítico é um processo que depende do tempo, da temperatura e é normalmente, controlado pela presença de partículas finas dispersas como o nitreto de alumínio (AIN) (SILVA, 2010).

\section{1 - Refino de grão através da alteração da composição química}

Um fator de extrema importância é a garantia de que a precipitação do nitreto de alumínio ocorra durante a laminação de acabamento para que seja garantido o não crescimento do grão austenítico. A temperatura em que os precipitados dissolvem completamente depende da composição química do aço e pode ser calculada a partir de dados termodinâmicos.

Para precipitados simples é possível expressar estas temperaturas na forma de equações simples, chamadas de equações de produto de solubilidade (Krauss, 2005).

$$
\begin{gathered}
A l+N=A l N \\
\log [\% A l][\% N]=\frac{-7400}{T}+1,95
\end{gathered}
$$

Outros elementos presentes no aço podem alterar a temperatura de dissolução dos precipitados. Softwares de simulação termodinâmica como ThermoCalc ${ }^{\circledR}$ ou de simulações considerando a cinética como o MatCalc ${ }^{\circledR}$ utilizam todos os elementos em seus resultados.

O objetivo principal foi caracterizar e melhorar a microestrutura perlítica do aço SAE 1070 laminado a quente produzido na Aperam visando reduzir ou eliminar o custo adicional dos clientes de relaminação durante o processamento em suas linhas de produção.

\section{MATERIAIS E MÉTODOS}

Foram utilizadas amostras de aços SAE 1070 produzidos na Aperam bobinas laminadas a quente na espessura de $2,25 \mathrm{~mm}$ com diferentes relações de alumínio e nitrogênio para os ensaios.

Também foram utilizadas amostras de bobina laminada a quente do aço SAE 1070 na espessura de $3,00 \mathrm{~mm}$ fabricada por outra empresa para níveis de comparação. Os materiais foram caracterizados de acordo com o seguinte procedimento:

- Análises de composição química e simulação termodinâmica;

- Análises do nível de inclusão e medição do tamanho de grão austenítico;

- Caracterização da microestrutura via Microscopia Ótica, Microscopia Eletrônica de Varredura (MEV) e determinação do espaçamento interlamelar individual e médio;

- Medição das propriedades mecânicas e ensaio de laminação a frio.

As amostras produzidas por outra empresa foi identificada como Aço $A_{0}$ e as amostras produzidas pela Aperam foram identificadas como Aço $A_{1}$ (produto padrão) e $\mathrm{A}_{2}$ (produto experimental). 


\section{RESULTADOS E DISCUSSÃO}

\section{1 - Análises de composição química e Simulação Termodinâmica}

A tabela 1 mostra a composição química das amostras utilizadas no estudo. Observa-se uma variação no teor de Al e N. É possível observar que a quantidade de alumínio no $A c ̧ o A_{0}$ é maior do que no $A_{c ̧ o} A_{1}$ e $A_{2}$, enquanto que a quantidade de nitrogênio no aço $A_{0}$ é menor do que no aço $A_{1}$ e $A_{2}$.

Tabela 1. Composição química do aço SAE 1070 utilizado

\begin{tabular}{ccccccccc}
\hline Origem & $\mathbf{C}(\%)$ & $\mathbf{M n}(\%)$ & $\mathbf{S i}(\%)$ & $\mathbf{P}(\%)$ & $\mathbf{S}(\%)$ & $\mathbf{C r}(\%)$ & $\mathbf{A l}(\%)$ & $\mathbf{N}(\%)$ \\
\hline Aço $A_{0}$ & 0,6903 & 0,7284 & 0,1833 & 0,0156 & 0,002 & 0,1833 & 0,0447 & 0,0040 \\
\hline Aço $_{1}$ & 0,7231 & 0,6925 & 0,2370 & 0,0170 & 0,0012 & 0,1915 & 0,0175 & 0,0067 \\
\hline Aço $_{2}$ & 0,7219 & 0,6920 & 0,2321 & 0,009 & 0,0005 & 0,1728 & 0,0194 & 0,0095 \\
\hline
\end{tabular}

De acordo com os resultados de composição química das amostras fez-se a simulação através do Software ThermoCalc ${ }^{\circledR}$ para verificar as possíveis fases formadas.

Na figura 2 é possível observar simulação de formação de nitreto de alumínio no Aço $\mathrm{A}_{1}$ e $\mathrm{A}_{2}$.

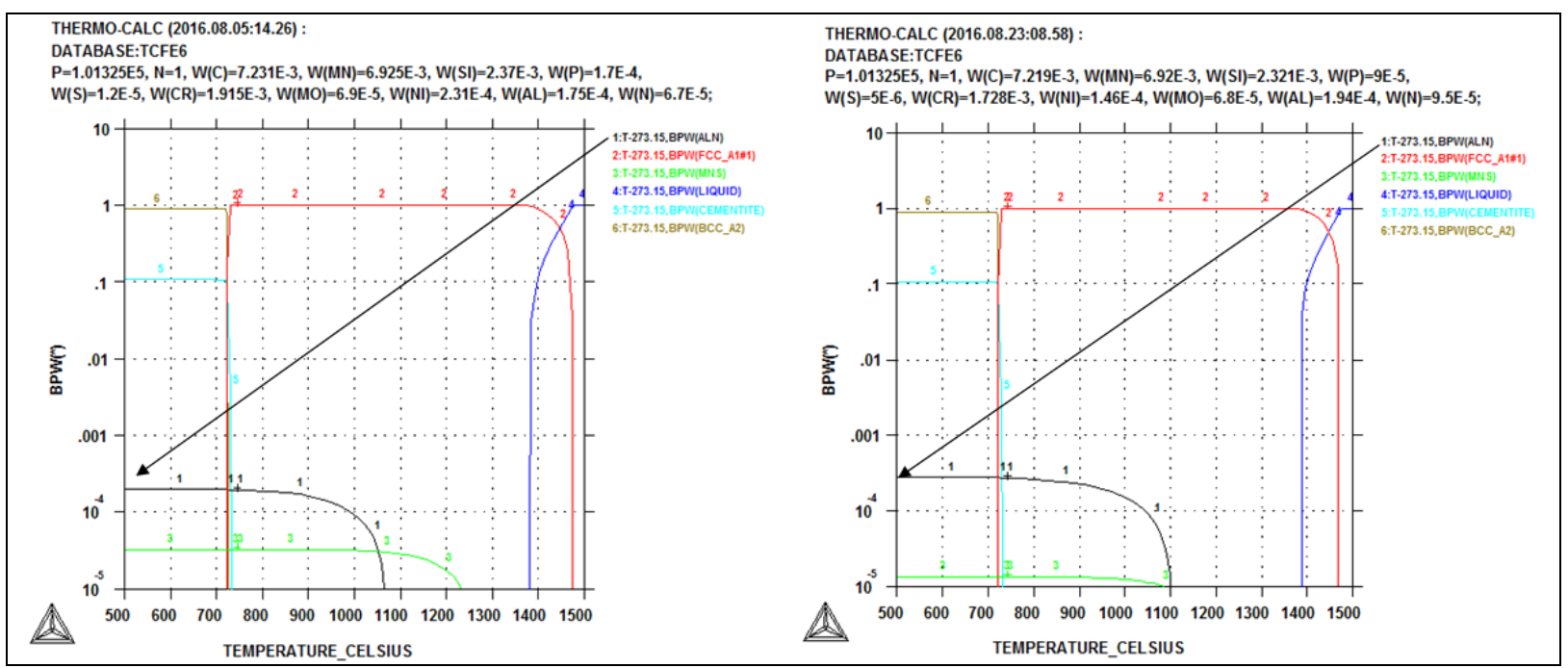

Figura 2. Simulação da possível quantidade de nitreto de alumínio formado no $A_{c ̧ o ~} A_{1}$ e $A_{2}$ através do software ThermoCalc ${ }^{\circledR}$.

Na figura 3 é possível observar simulação de formação de nitreto de alumínio no Aço $A_{0}$. O aumento do alumínio na composição sem o aumento do nitrogênio não tem efeito na formação de nitreto de alumínio e como consequência, não terá efeito de refino de grão austenítico por partículas finas dispersas. 


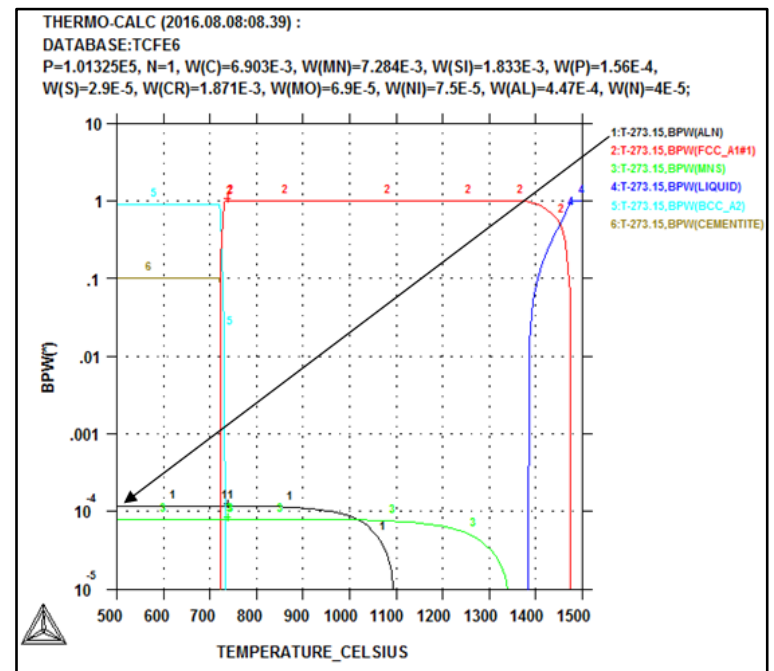

Figura 3. Simulação da possível quantidade de nitreto de alumínio formado no Aço $A_{0}$ através do software ThermoCalc ${ }^{\circledR}$.

\section{3 - Análises do nível de inclusão e medição do tamanho de grão austenítico}

O Aço $A_{0}$ mostrou níveis de inclusão maiores que o $A_{c ̧ o ~} A_{1}$ e $A_{2}$ de acordo com a norma ASTM E45, porém abaixo do máximo de 3,0 conforme tabela 2. O menor nível de limpidez do material $A_{0}$ não mostrou relação com o maior teor de alumínio contido no aço, pois o nível de inclusões de alumina visto foi zero.

Tabela 2. Caracterização de inclusões conforme norma ASTM E45

\begin{tabular}{lccc}
\hline \multicolumn{1}{c}{ Classificação } & Aço $\mathbf{A}_{\mathbf{0}}$ & Aço $\mathbf{A}_{\mathbf{1}}$ & $\mathbf{A c ̧ o ~}_{\mathbf{A}}$ \\
\hline A - Sulfeto & 2,5 & 1,5 & 1,5 \\
\hline B - Alumina & 0,0 & 0,0 & 0,0 \\
\hline C - Silicato & 0,0 & 0,0 & 0,0 \\
\hline D - Óxido Globular & 1,0 & 1,0 & 1,0 \\
\hline
\end{tabular}

O tamanho de grão austenítico foi medido por comparação conforme a norma ASTM E112 nos aços e os resultados estão mostrados na tabela 3. O menor tamanho de grão observado no Aços $A_{0}$ não possui relação direta com a formação de nitreto de alumínio e sim com o processo produtivo. O menor tamanho de grão no $A_{c ̧ o} A_{2}$ em relação ao Aço $A_{1}$ comprova a melhor relação de alumínio e nitrogênio utilizado.

Tabela 3. Tamanho de grão encontrado nos aços ensaiados

\section{Tamanho de grão}

\begin{tabular}{cccc}
\hline & Aço $\mathbf{A}_{\mathbf{0}}$ & Aço $\mathbf{A}_{\mathbf{1}}$ & Aço $\mathbf{A}_{\mathbf{2}}$ \\
\hline Mais Frequente & 8,0 & 7,0 & 9,0 \\
\hline Menos Frequente & 8,5 & 8,0 & 9,0 \\
\hline Diâmetro médio & $16,8 \sim 22,5 \mu \mathrm{m}$ & $22,5 \sim 31,8 \mu \mathrm{m}$ & $15,90 \mu \mathrm{m}$ \\
\hline
\end{tabular}

\section{4 - Análises de microestrutura via Microscopia Ótica e Microscopia Eletrônica de Varredura (MEV)}

A microestrutura visualizada através de microscopia ótica com aumento de 1000x em todas as amostras analisadas foi perlita fina, demonstrando similaridade microestrutural. As microestruturas são mostradas nas figuras 4 e 5 . 


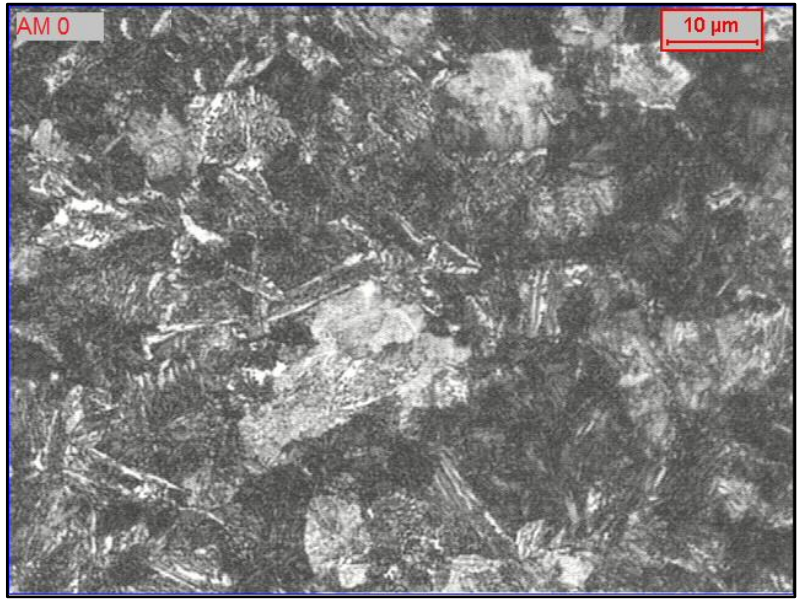

Figura 4. Microestrutura encontrada no Aço $A_{0}$ com aumento de $1000 x$ e ataque Nital $5 \%, 8$ segundos.

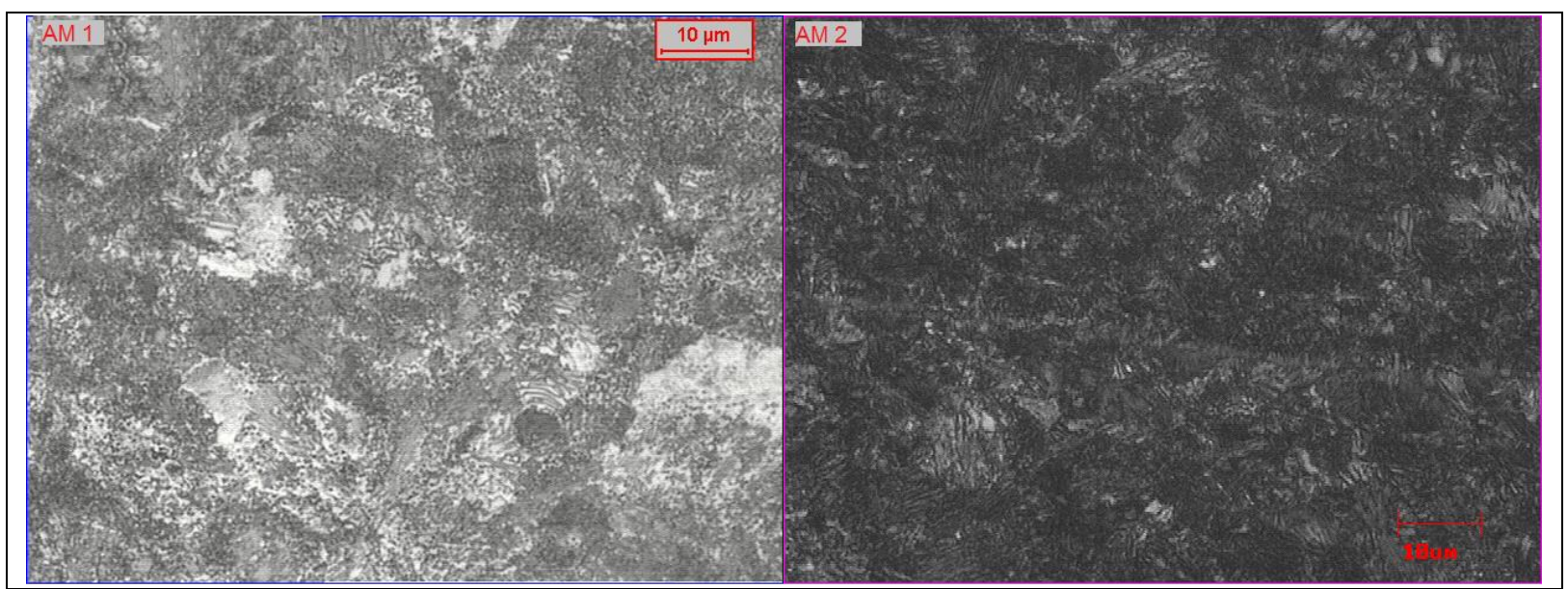

Figura 5. Microestrutura encontrada no $A_{c ̧ o} A_{1}$ e $A_{2}$ com aumento de 1000x e ataque Nital 5\%, 8 segundos.

O Microscópio Eletrônico de Varredura (MEV) possibilitou diferenciar a microestrutura e a medição do espaçamento interlamelar médio. A microestrutura visualizada na amostra do Aço $A_{0}$ foi predominantemente perlítica com diferente morfologia em relação aos Aços $A_{1}$ e $A_{2}$. É possível observar que as lamelas não são bem definidas. Mostram-se lamelas fragmentadas e de difícil localização de regiões ideais para medição do espaçamento interlamelar conforme figura 6 e 7 .

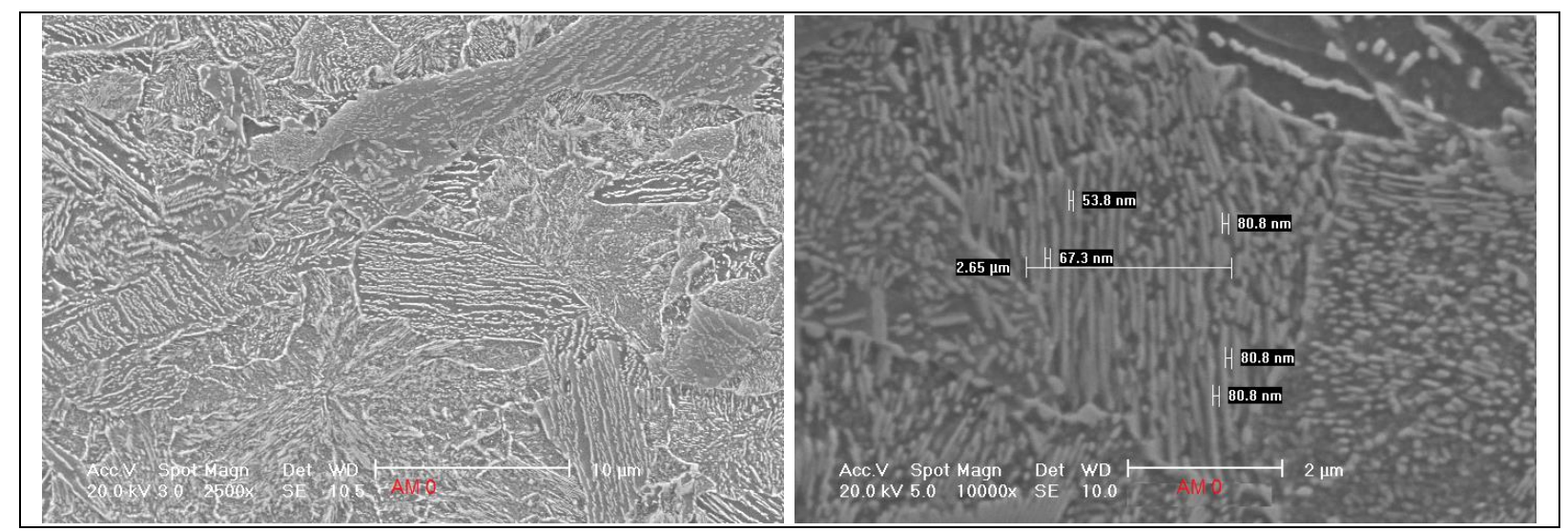

Figura 6. Microestrutura no Aço $A_{0}$ com aumento de 2500x e 10.000x através do Microscópio Eletrônico de Varredura (MEV). 


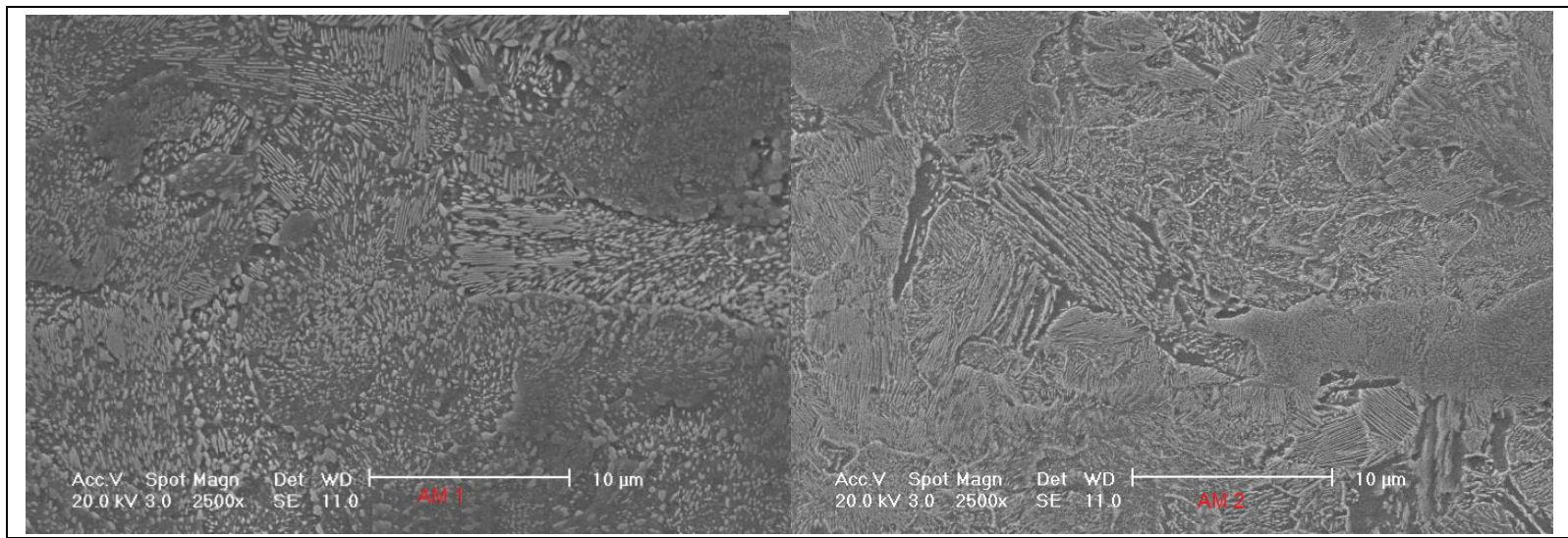

Figura 7. Microestrutura no Aço $A_{0}$ com aumento de 2500x e 10.000x através do Microscópio Eletrônico de Varredura (MEV).

Para determinação do espaçamento interlamelar foi realizado 5 medições individuais em 3 regiões de cada corpo de prova e traçou-se uma linha com comprimento conhecido e dividiu-se o comprimento desta linha pelo número de lamelas de cementita cortadas pela linha. O espaçamento interlamelar médio considerado foi 0 resultado desta divisão. Os resultados podem ser vistos na tabela 4.

Considerando o desvio padrão, pode se afirmar que o espaçamento interlamelar entre as amostras não diferem.

Tabela 4. Espaçamento interlamelar médio

\begin{tabular}{|c|c|c|c|c|c|c|}
\hline \multicolumn{7}{|c|}{ Espacamento interlamelar ( $\mu \mathrm{m})$} \\
\hline & \multicolumn{3}{|c|}{ Medida individual } & \multicolumn{3}{|c|}{ Cálculo pela linha } \\
\hline & $A c ̧ o A_{0}$ & Aço $A_{1}$ & Aço $A_{2}$ & $A c ̧ o A_{0}$ & Aço $A_{1}$ & Aço $A_{2}$ \\
\hline Média & 0,095 & 0,097 & 0,092 & 0,149 & 0,140 & 0,0139 \\
\hline Desvio Padrão & 0,015 & 0,022 & 0,026 & 0,040 & 0,025 & 0,025 \\
\hline
\end{tabular}

\section{5 - Medição das propriedades mecânicas e ensaios de laminação a frio.}

Os resultados de propriedade mecânica são mostrados na tabela 5. É possível observar que o Aço $A_{0}$ demonstrou melhor resultado em relação ao $A_{c ̧ o} A_{1}$, porém o Aço $A_{2}$ demonstrou melhor resultado em relação ao $A$ ço $A_{0}$. Com base nesses resultados é possível afirmar que o fator espaçamento interlamelar não teve não teve influencia nas propriedades mecânicas dos materiais analisados e sim o fator menor tamanho de grão, pois o espaçamento nas amostras não difere.

Tabela 5. Resultado médio de propriedade mecânica das amostras ensaiadas

\begin{tabular}{cccc}
\hline & Aço $_{\mathbf{0}}$ & Aço $_{\mathbf{1}}$ & Aço $_{\mathbf{1}}$ \\
\hline LE $(0,2 \%)[\mathrm{MPa}]$ & 681 & 625 & 713 \\
\hline LR $[\mathrm{Mpa}]$ & 968 & 919 & 1066 \\
\hline Dureza $[\mathrm{HRc}]$ & 30 & 27 & 32 \\
\hline
\end{tabular}

A amostra do Aço $A_{0}$ foi laminada a frio no laminador piloto do Centro de Pesquisas da Aperam partindo-se da espessura inicial de $3,11 \mathrm{~mm}$. Foi laminado até a espessura de $1,86 \mathrm{~mm}$ que equivale a $40 \%$ de redução sem o aparecimento de trincas. O material suportaria mais reduções e estava distante dos limites do laminador, se destacando em termos de laminabilidade a frio. Após foi realizado novos ensaios mecânicos. 
As amostras do Aço $A_{1}$ foram laminadas partindo-se da espessura inicial de $2,25 \mathrm{~mm}$. Foi laminado até $1,46 \mathrm{~mm}$ que equivale a $35 \%$ de redução. Foi necessário interromper o ensaio em função de desarmes do laminador piloto por excesso de carga.

As amostras do Aço $A_{2}$ foram laminadas partindo-se da espessura inicial de $2,00 \mathrm{~mm}$. Foi laminada até $1,10 \mathrm{~mm}$ que equivale a $45 \%$ de redução sem 0 aparecimento de trincas. Todas as amostras atingiram $45 \%$ de redução sem a ocorrência de trincas nas bordas e distante dos limites do laminador. Após atingir esse nível de redução paralisou-se o ensaio para retirada de amostras para ensaio de tração.

Os resultados de ensaio de tração no material encruado são mostrados na tabela 6. É possível observar que a razão elástica do aço $A_{0}$ encontrada foi de 0,93 após a redução a frio de $40 \%$, nas amostras do Aço $A_{1}$ a razão elástica foi de 0,97 após $35 \%$ de redução, sendo o pior resultado. Porém as amostras do Aço $A_{2}$ apresentaram razão elástica de 0,95 após a redução a frio de $45 \%$, ou seja, após uma maior redução a frio. Por esse critério o Aço $A_{2}$ se mostrou similar ao aço AMT. É notável o aumento do limite de escoamento, o limite de resistência e a dureza do aço Aperam mostrando-se superior ao aço AMT.

Tabela 6. Resultados de laminação a frio e ensaios mecânicos do material encruado

\begin{tabular}{cccc}
\hline & Aço A $_{\mathbf{0}}$ & Aço $_{\mathbf{1}}$ & Aço $_{\mathbf{2}}$ \\
\hline Redução [\%] & 40 & 35 & 45 \\
\hline LE $(0,2 \%)[\mathrm{MPa}]$ & 1177 & 1175 & 1313 \\
\hline LR [Mpa] & 1261 & 1212 & 1380 \\
\hline LE / LR & 0,93 & 0,97 & 0,95 \\
\hline Coef. Encruamento $(\mathrm{n})$ & $0,08+/-0,01$ & 0,08 & $0,09+/-0,01$ \\
\hline Dureza $[\mathrm{HRc}]$ & 33 & 32 & 37 \\
\hline
\end{tabular}

\section{CONCLUSÃO}

- Após caracterização e ensaios realizados na amostra do aço carbono SAE 1070 foi possível observar que o aço de outros fornecedores possuíam melhores propriedades mecânicas e melhor laminabilidade a frio em relação ao aço Aperam padrão.

- Através do Software Thermo-Calc foi possível verificar as fases formadas tanto no aço Aperam quanto no aço concorrente. A partir desses resultados buscou uma melhor relação para uma maior formação de nitretos de alumínio sem a necessidade do aumento considerável do teor de alumínio que se torna crítico no processo de aciaria da Aperam em função do diâmetro da válvula submersa e do risco de formação do spinel $\left(\mathrm{Al}_{2} \mathrm{O}_{3} \cdot \mathrm{MgO}\right)$.

- Através dos ensaios foi possível observar uma melhora significativa do aço Aperam experimental em relação ao aço Aperam padrão. Houve melhora significativa das propriedades mecânicas e da laminabilidade a frio. 
- Foi possível confirmar que os melhores resultados não são em função apenas do espaçamento interlamelar da perlita e sim do fator menor tamanho de grão austenítico que garantem melhores propriedades mecânicas.

- O software ThermoCalc se mostrou uma ferramenta eficiente e confiável na simulação de formação de fases que possibilitou um melhor ajuste da composição química do aço para a redução do tamanho de grão austenítico.

- O aço SAE 1070 laminado a quente produzido na Aperam, constituído de uma microestrutura perlítica fina com menor tamanho de grão austenitico poderá permitir maiores reduções de espessura no processo de laminação a frio de seus clientes visando a eliminação do processo intermediários de recozimento.

\section{REFERÊNCIAS}

1 Sereno A.; Bomfim AF; Rodrigues FJS; Alves GG; Anjos RT; Perim CA; Junior JF.

Desenvolvimento do aço SAE 1070 na Arcelor Mittal Tubarão e análise da comformabilidade através da relaminação na Brasmetal Waelzholz. In: 50 Seminário de Laminação da ABM. Ouro Preto - MG, 2013.

2 Camargo LF. Estudo da deformação a frio dos aços eutetóides com microestrutura perlítica fina e perlítica grosseira [monografia]. São Paulo: Universidade Presbiteriana Mackenzie; 2012.

3 Colpaert H; Silva ALVC. Metalografia dos produtos siderúrgicos comuns. 4. ed., rev. e atual. São Paulo: E. Blucher, 2008. xx, 652 p. ISBN

4 Silva, ALVC; Mei PR. Aços e ligas especiais. 3. ed., rev. São Paulo: Blucher, 2010. 646 p. ISBN

5 Krauss G. Steels: Processing, Structure, and Performance. ASM International, $2^{\mathrm{a}}$ Ed., Metals Park, Ohio, 2005. 